\title{
Kallikrein gene expression in the gonadotrophin-stimulated rat ovary
}

\author{
A M Holland, J K Findlay and J A Clements ${ }^{\mathbf{1}}$ \\ Prince Henry's Institute of Medical Research, PO Box 5152 Clayton, Victoria 3168, Australia \\ ${ }^{1}$ Centre for Molecular Biotechnology, School of Life Sciences, Queensland University of Technology, Brisbane 4011, Australia \\ (Requests for offprints should be addressed to A M Holland, Walter and Eliza Hall Institute of Medical Research, Post Office, Royal Melbourne Hospital, \\ Parkville, Victoria 3052, Australia; Email: holland@wehi.edu.au)
}

\begin{abstract}
The kallikreins (KLKs) are a highly conserved multi-gene family of serine proteases that are expressed in a wide variety of tissues and act on a diverse range of substrates. KLK-like enzyme activity has variously been reported to increase or decrease during the period leading up to ovulation in the equine chorionic gonadotrophin (eCG)primed, human chorionic gonadotrophin (hCG)-stimulated immature rat ovary. These earlier studies, which used biochemical assays to detect enzyme activity, lacked the specificity and sensitivity necessary to characterise conclusively the activity of the individual $K L K$ gene family members. In this study, we have used a gene-specific RT-PCR/Southern hybridisation strategy to delineate the
\end{abstract}

expression patterns of six of the individual $K L K$ genes expressed in the rat ovary (rKLK1-3 and $r K L K 7-9)$. We have identified three broad patterns of expression in the eCG/hCG-stimulated ovary in which there is either a post-eCG increase/pre-ovulatory decrease in $r K L K$ expression $(r K L K 1, r K L K 3)$, a peri-ovulatory decrease in expression $(r K L K 2, r K L K 8)$ or a relatively unchanged pattern of expression ( $r K L K 7, r K L K 9)$. In addition to clarifying the earlier biochemical studies, these findings support a differential role for the individual KLKs in the ovulatory process.

Journal of Endocrinology (2001) 170, 243-250

\section{Introduction}

The complex process of mammalian ovulation requires the cyclical growth of the follicle, and maturation and expulsion of the oocyte followed by formation of the corpus luteum. The physiological and endocrinological changes occurring throughout this fundamental process have been well understood for many years, but it is only relatively recently that some of the mechanisms underlying these changes have been elucidated. A number of factors involved locally in the ovulatory process have been identified, including tissue remodelling enzymes, vasoactive peptides and growth factors (Skinner \& Parrot 1994, Tsfariri 1995, Tsfariri \& Reich 1999). Numerous cytokines and mediators of inflammation have also been implicated, leading to the proposition that ovulation bears many of the hallmarks of an inflammatory response (Espey 1990, Terranova \& Rice 1997, Adashi 1998, Tamura et al. 1998).

The kallikreins are a multigene $(K L K)$ family of serine proteases with high sequence homology to tissue kallikrein and are expressed in a wide variety of tissues (Clements 1989). They exhibit a diverse range of enzymatic functions, in spite of their highly conserved sequence, and are involved in the post-translational processing of polypeptides to their active or inactive forms. For example, tissue kallikrein releases the multi-functional peptide (lys-) bradykinin, which is involved in a variety of biological responses, including the regulation of blood flow and vascular permeability at the site of tissue damage in inflammatory responses (Bhoola et al. 1992). In vitro, tissue kallikrein can also activate the matrix metalloproteinases, pro-collagenase and pro-gelatinase (Menashi et al. 1994, Tsfariri 1995). Other functionally characterised members of the kallikrein family include enzymes that generate vasoactive peptides and growth factor processing enzymes (Clements 1989, Bhoola et al. 1992, Clements et al. 1997). Thus, this family of enzymes are involved in a diverse range of biological responses.

Kallikrein-like enzyme activity has variously been reported to increase or decrease during the period leading up to ovulation in the well-established ovulatory model - the equine chorionic gonadotrophin (eCG)-primed, human chorionic gonadotrophin (hCG)-stimulated immature rat (Espey et al. 1986, 1989, Gao et al. 1992). These studies, in which kallikrein activity was assessed by either kinin generation (Espey et al. 1986) or cleavage of chromogenic substrates (Espey et al. 1989, Gao et al. 1992, Tanaka et al. 1992), lacked the specificity and sensitivity necessary to identify conclusively the individual kallikrein gene family 
member(s) responsible for the observed activity. However, as these changes in enzyme activity were detected at around the time of ovulation and were inhibited by administration of the anti-ovulatory and anti-inflammatory agent, indomethacin, it was postulated that kallikrein or a kallikrein-like enzyme may play a role in the process of ovulation, and in particular, the inflammatory-like changes that occur during this process.

The rat $K L K$ gene family consists of 13 genes, of which three are pseudogenes (Clements 1989). We have previously demonstrated that six members of the rat $K L K$ gene family $(r K L K 1, r K L K 3, r K L K 7, r K L K 8, r K L K 9$ and $r K L K 12$ ) are expressed in the rat ovary (Clements et al. 1995). In this study, we have used a sensitive and specific semi-quantitative RT-PCR/Southern hybridisation strategy to delineate the expression patterns of the individual $r K L K$ gene family members in the eCG-primed, hCGstimulated immature rat model of ovulation in order to relate the previous enzymic data (Espey et al. 1986, 1989, Gao et al. 1992) to the expression of specific kallikrein genes. We have also used a semi-quantitative RT-PCR analysis of luteinising hormone receptor (LH-R) and follicle stimulating hormone receptor (FSH-R) expression, similar to that used by Camp et al. (1991), to confirm the efficacy of the eCG/hCG treatment.

\section{Materials and Methods}

\section{Animals/drug treatments}

Twenty-one to 23-day-old immature female SpragueDawley rats were kept under a $12 \mathrm{~h}$ darkness: $12 \mathrm{~h}$ light cycle; rat chow and water were available ad libitum. The immature rats, $n=4$ per group, were injected s.c. with 10 IU eCG (eCG; Folligon, Intervet, NSW, Australia) in saline or saline alone (control group) at $0830 \mathrm{~h}$. After $48 \mathrm{~h}$, 10 IU hCG (Chorulon, Intervet, NSW, Australia) was injected s.c. In this model, previously validated in our laboratory (J McMaster \& J K Findlay, unpublished observations; Clements et al. 1995), the number of ova shed per ovary ranges from 17 to 40 , and ovulation occurs between 10 and 12 hours after hCG administration. Animals were killed at $0,2,4,8,10,12,16,20$ or $30 \mathrm{~h}$ after hCG administration and tissues collected. This experiment was performed on two separate occasions. These experiments were approved by the Monash Medical Centre Animal Ethics Committee and performed in accordance with the National Health and Medical Research Council of Australia guidelines on animal experimentation.

\section{Semi-quantitative RT-PCR}

RNA was prepared essentially according to the procedure of Chomczynski \& Sacchi (1987), except that the RNA was finally precipitated with 2 vol $4 \cdot 5 \mathrm{M}$ sodium acetate
$(\mathrm{pH} 7)$ at $-20{ }^{\circ} \mathrm{C}$ for $1 \mathrm{~h}$ to eliminate any further residual DNA. First-strand cDNA was synthesised as follows: $500 \mathrm{ng}$ ovarian total RNA was heated to $65^{\circ} \mathrm{C}$ for $5 \mathrm{~min}$ before addition of a reaction mix containing $1 \times \mathrm{PCR}$ buffer $(50 \mathrm{mM} \mathrm{KCl} ; 10 \mathrm{mM}$ Tris, $\mathrm{pH} 8 \cdot 0$; 0.1\% TritonX100), $6 \mathrm{mM} \mathrm{MgCl}$; $1 \mathrm{mM}$ each dATP, dCTP, dTTP, dGTP; 25 pmol p(dT)15; 20 U RNasin (Promega) and $5 \mathrm{U}$ AMV-RT (Boehringer-Mannheim, Nunawading, Victoria, Australia) in a final volume of $20 \mu$ l. Reactions were incubated at $42{ }^{\circ} \mathrm{C}$ for $60 \mathrm{~min}$. The enzyme was then denatured by heating to $95^{\circ} \mathrm{C}$ for $3 \mathrm{~min}$, before adding the cDNA to the PCR reaction.

Semi-quantitative PCR conditions were established for both the LH and FSH receptor and kallikrein genes using a modified procedure based on our previous study (Clements et al. 1995) and the method established by Camp et al. (1991). The latter method has become widely used in semi-quantitative RT-PCR studies (Orly et al. 1996, Nemeth et al. 1998, Ronan-Fuhrman et al. 1998).

\section{PCR analysis of KLK multigene family expression}

Primers were designed to highly conserved common sequences in exons 2 (sense primer: 5'ACTGGAATT CGAATTCCGAACCCTGGCAAGT3') and 4 (antisense primer: 5'GCTAGGATCCGATGTTCACACA CTGGAGATC3') of the rat $K L K$ genes such that all gene family members were amplified in the same reaction to give a PCR product of $426 \mathrm{bp}$ (Clements et al. 1995). A second set of primers (sense 5'TCTACATCCTGG CTCACACTG3'; antisense: 5'AGAAGATGGTGTGC TCATTGC3') (Cole et al. 1989) was used to amplify a $228 \mathrm{bp}$ PCR product from the ubiquitously expressed $\beta_{2}$-microglobulin gene as an internal control to correct for any loading differences between samples. PCR conditions were optimised by determining the appropriate number of cycles of amplification and amount of RNA required for both the kallikrein and control PCR products to be amplified in the linear reaction range (data not shown). Optimal PCR conditions using 25 pmol universal KLK primers were: $4 \mu \mathrm{l}$ cDNA (an equivalent of $100 \mathrm{ng}$ total RNA) amplified at $95^{\circ} \mathrm{C}$ for $1 \mathrm{~min}, 50{ }^{\circ} \mathrm{C}$ for $2 \mathrm{~min}$, $72{ }^{\circ} \mathrm{C}$ for 3 min over 30 cycles. The $\beta_{2}$-microglobulin sense and antisense primers $(25 \mathrm{pmol})$ were added to the reactions after the seventh cycle of amplification, such that $\beta_{2^{-}}$microglobulin products were amplified for 22 cycles only.

\section{Southern blot analysis}

Fifteen microlitres of the PCR products were electrophoresed and Southern blotted by standard procedures. Blots were hybridised with either a cRNA probe (KLK1 or $\beta_{2}$-microglobulin cDNA) at $50{ }^{\circ} \mathrm{C}$ overnight or gene-specific oligonucleotide probes for $r K L K 1, r K L K 3$, $r K L K 7, \quad r K L K 8, \quad r K L K 9$ or $r K L K 12$ as previously 
described (Clements et al. 1995) at $37^{\circ} \mathrm{C}$ overnight. Blots were washed at a stringency of $0.1 \times \mathrm{SSC}, 0 \cdot 1 \% \mathrm{SDS}$ at $50{ }^{\circ} \mathrm{C}$ (for cRNA probes) or $2 \times \mathrm{SSC}, 0 \cdot 1 \% \operatorname{SDS}$ at $37^{\circ} \mathrm{C}$ (for oligo probes) before autoradiography. Hybridised membranes were also scanned on a Fuji phosphoimager system and analysed using the MacBas image analysis software program. The final KLK expression patterns, as assessed by densitometry, were normalised relative to each individual $\beta_{2}$-microglobulin expression level and plotted as corrected integrated optical density as a function of treatment. Statistical analysis was performed by one-way analysis of variance (ANOVA) using Prism (GraphPad Software Inc., San Diego, CA, USA).

\section{PCR analysis of LH-R and FSH-R}

A modified version of the semi-quantitative RT-PCR assay for the expression of LH-R and FSH-R established by Camp et al. (1991) was used in these studies. Reaction conditions were optimised for the appropriate amount of RNA and number of amplification cycles as for the kallikrein semi-quantitative RT-PCR assay. Briefly, oligonucleotide primer pairs designed to the LH-R (sense: 5'GAGCTGACAGCTCCTAACAAG3'; antisense: 5'CC ACCGAGAGCGTTAACTCAC3'), FSH-R (sense 5'ACCATTGTGTCCTCATCAAGC3'; antisense: 5'GAAA CCTCATCCGCTACCCAC3') (primer sequences kindly provided by Dr K Mayo) and $\beta_{2}$-microglobulin genes (in place of the ribosomal protein RPL-19 internal standard used by Camp et al. (1991)) were used to amplify PCR products of $419 \mathrm{bp}$ (LH-R), $311 \mathrm{bp}$ (FSH-R) and $228 \mathrm{bp} \quad\left(\beta_{2^{-}}\right.$ microglobulin). LH- and FSH-R products were amplified for 28 cycles of $95{ }^{\circ} \mathrm{C}$ for $1 \mathrm{~min}, 65^{\circ} \mathrm{C}$ for $2 \mathrm{~min}, 72^{\circ} \mathrm{C}$ for $3 \mathrm{~min}$ followed by extension at $72{ }^{\circ} \mathrm{C}$ for $10 \mathrm{~min}$, and $\beta_{2}$-microglobulin products were amplified in the same reactions for 24 cycles.

Radiolabelled $\alpha-\left[{ }^{32} \mathrm{P}\right] \mathrm{dCTP}$ was incorporated into the PCR to enable direct detection of PCR products. An aliquot $(5 \mu \mathrm{l})$ of the RT-PCR product was electrophoresed on a $6 \%$ denaturing polyacrylamide gel. Vacuum-dried polyacrylamide gels were then scanned on a Fuji phosphoimager system and analysed as described above.

\section{Results}

Confirmation of the hormonal status of the gonadotrophinstimulated rat model of ovulation

The patterns of expression of the LH-R and FSH-R were determined in the two separate experiments in order to confirm the hormonal status of the animals and to validate the semi-quantitative assay approach by direct comparison with the earlier findings of Camp et al. (1991) (Fig .1). The results of one of these experiments is shown in Fig. 1; however, both animal experiments gave similar results and showed the expected patterns of expression of these two gonadotrophin receptor mRNAs, consistent with those observed by Camp et al. (1991). The level of LH-R expression was increased after eCG administration, peaking at $2 \mathrm{~h}$ after hCG administration in both experiments before mRNA levels decreased to the expected basal values by $12 \mathrm{~h}$ post-hCG, around the time of ovulation, as was described previously (Camp et al. 1991). As expected, FSH-R expression did not change as markedly as that of the LH-R, with a moderate increase in mRNA levels after eCG administration, before decreasing to a stable low level of expression at around $12 \mathrm{~h}$ post-hCG.

\section{Characterisation of KLK gene expression}

The results obtained in the two animal experiments were essentially the same; the results of one experiment are shown in Figs 2 and 3. Initially, RT-PCR products were probed with a $r K L K 1 \mathrm{cRNA}$ probe to detect the expression pattern of all $r K L K$ genes (Fig. 2). Although the Southern blots show some intergroup variation and variation in the levels of $\beta_{2}$-microglobulin mRNA expression, there is a clear pattern of $K L K$ expression that is also apparent in the $\beta_{2}$-microglobulin normalised $K L K$ expression levels illustrated in the chart in Fig. 2. KLK expression patterns, although variable early in the experimental period, showed a decrease in $r K L K$ mRNA levels after eCG administration, followed by an increase briefly at $2 \mathrm{~h}$ after hCG administration, before continuing to decrease throughout the pre-ovulatory period until just before the time of ovulation at around $10 \mathrm{~h}$. The $r K L K$ mRNA levels then remained at this significantly lower value (compared with control groups) until $30 \mathrm{~h}$ after hCG treatment.

The patterns of expression of the individual $r K L K$ genes were subsequently delineated by hybridisation of the RT-PCR products with gene-specific oligonucleotides. Although there was a considerable difference in the response of $r K L K 1$ and $r K L K 3$ to eCG treatment, (note different scales in Fig. 3), the patterns of gene expression observed for $r K L K 1$ and $r K L K 3$ (Fig. 3) after hCG stimulation were similar to the trend observed for the overall expression of the $r K L K$ genes as detected with the $r K L K 1 \mathrm{cRNA}$ probe (Fig. 2), with a post-hCG increase in expression followed by a significant decrease in $r K L K 1$ and $r K L K 3$ mRNA levels by the time of ovulation.

The patterns of expression observed for $r K L K 2, r K L K 7$, $r K L K 8$ and $r K L K 9$ (Fig. 3) were less clear than those described above for $r K L K 1$ and $r K L K 3$, with considerable intra-group variation observed for all of these genes throughout the ovulatory period. Low levels of expression were observed for both $r K L K 2$ and $r K L K 8$ throughout the pre- and post-ovulatory periods, before $r K L K 2$ expression was observed to increase significantly around $30 \mathrm{~h}$ after hCG administration (Fig. 3). A notable point in the relatively stable patterns of expression of $r K L K 2$ and $r K L K$ was their respective levels of peri-ovulatory gene 


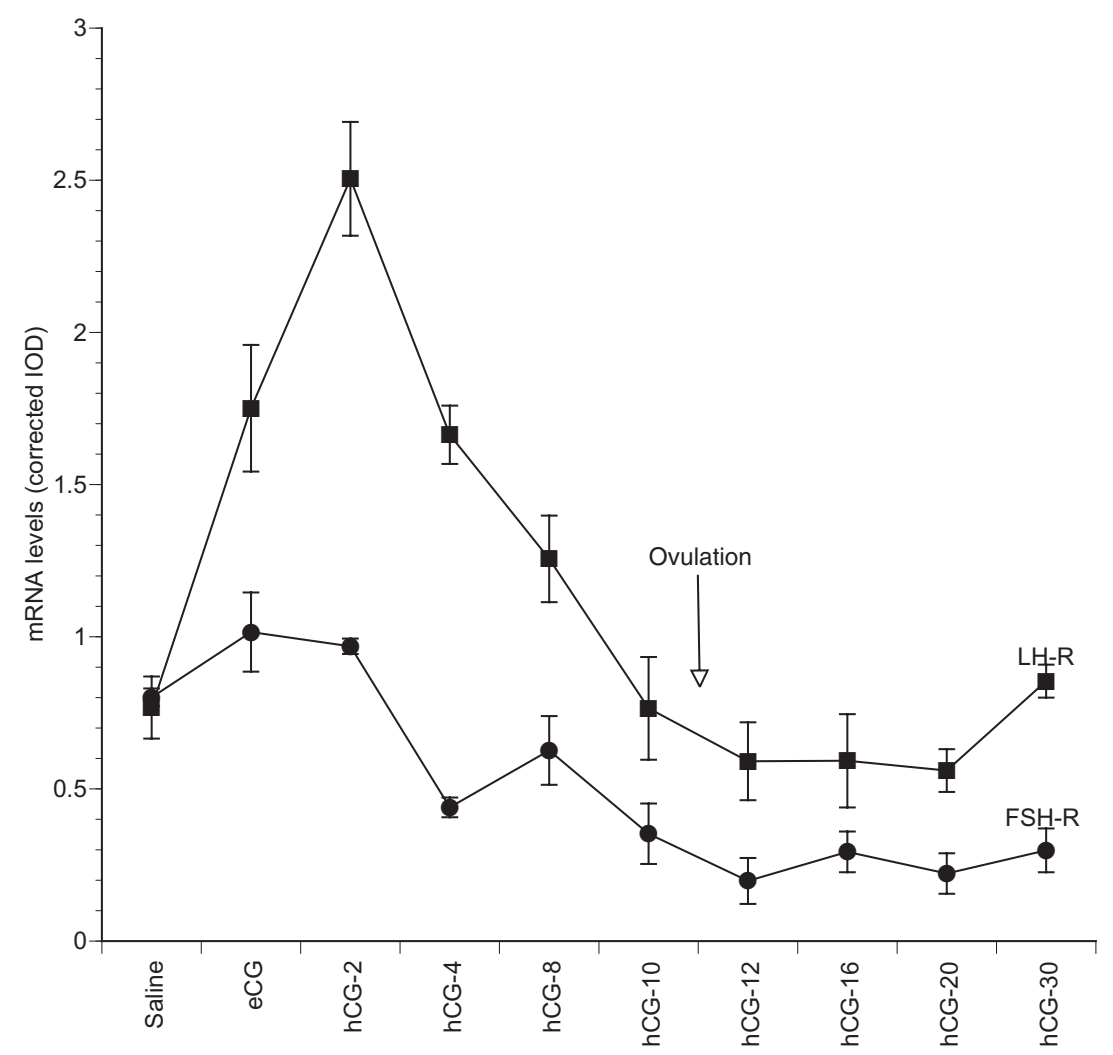

Figure 1 LH-R and FSH-R expression in the gonadotrophin-stimulated rat ovary. LH-R, FSH-R and $\beta_{2}$-microglobulin were reverse transcribed and co-amplified from 100 ng ovarian total RNA. RNA was obtained from the ovaries of saline-treated controls (saline), and after $48 \mathrm{~h}$ from animals treated with hCG for 0 (eCG), 2 (hCG-2), 4 (hCG-4), 8 (hCG-8), 10 (hCG-10), 12 (hCG-12), 16 (hCG-16), 20 (hCG-20) or $30 \mathrm{~h}$ (hCG-30). The arrow indicates the time of ovulation, which occurs at 10-12 h after hCG treatment in this model. Levels of LH-R and FSH-R expression as assessed by phosphorimage analysis were corrected by normalisation to $\beta_{2}$-microglobulin expression levels and plotted as corrected integrated optical density (IOD) (mean \pm S.E.M.) as a function of treatment.

expression. $r K L K 2$ expression decreased by $4-8 \mathrm{~h}$ post$\mathrm{hCG}$ administration, prior to an apparent increase in expression by $10 \mathrm{~h}$ post-hCG, whereas $r K L K 8 \mathrm{mRNA}$ was undetectable $10 \mathrm{~h}$ after hCG stimulation, before an upregulation of expression by $12 \mathrm{~h}$ post-hCG. Both these observations, although not significant $(P>0 \cdot 05)$, were consistent and reproducible.

The patterns of expression of both $r K L K 7$ and $r K L K 9$ were both characterised by relatively steady-state patterns of expression after eCG priming and hCG stimulation. The decrease in the level of $r K L K 9$ expression at $12 \mathrm{~h}$ post-hCG was consistent and reproducible, although it did not reach a level of significance compared with pre-ovulatory values $(P>0 \cdot 05$; Fig. 3$)$.

\section{Discussion}

This study has used a sensitive, semi-quantitative RTPCR assay to delineate the ovarian expression patterns of six members of the highly conserved KLK multi-gene family in the peri-ovulatory period of the rat. In using the eCG/hCG rat model of ovulation, we have first shown that the expression patterns of the LH-R and FSH-R are similar to those reported by Camp et al. (1991) and confirm the hormonal status of the animals, the physiological validity of the model and, importantly, demonstrate the reproducibility of the semi-quantitative RT-PCR approach.

Apart from the studies by Espey and Gao, in which kallikrein-like enzyme activity has previously been shown to be regulated in the gonadotrophin-stimulated rat ovary (Espey et al. 1989, Gao et al. 1992), the present study is the first attempt to determine regulatory changes in expression, at the mRNA level, of KLK gene family members in this model, and it has been able to elucidate further the patterns of expression of the individual $r K L K$ genes. We have identified three broad patterns of expression across the $r K L K$ gene family characterised by (i) a post-eCG increase/pre-ovulatory decrease in expression ( $r K L K 1$, 


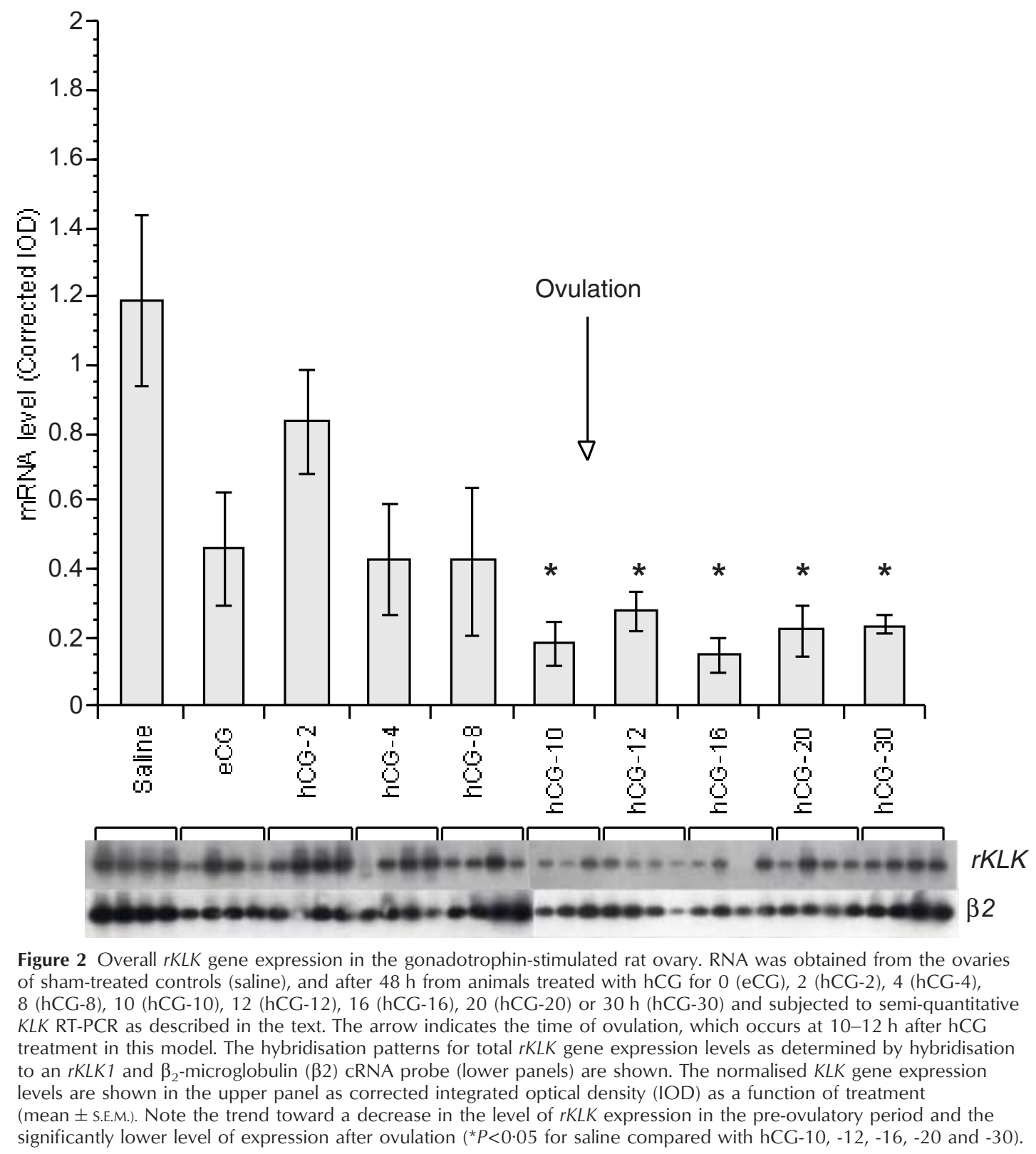

$r K L K 3$ ); (ii) a peri-ovulatory decrease, post-ovulatory increase in expression ( $r K L K 2$ and $r K L K 8)$ or (iii) a level of expression relatively unchanged by gonadotrophin stimulation ( $r K L K 7, r K L K 9)$.

After delineation of the patterns of expression of individual $K L K$ genes, we found that the pattern of kallikrein enzyme activity detected in the previous study by Gao et al. (1992), in which kallikrein enzyme activity was greatest immediately after hCG administration in the pregnant mare's serum gonadotrophin-primed immature rat ovary, before decreasing to a minimal level just before ovulation, was more consistent with the pattern of $r K L K 1$ gene expression detected in this study than in that by Espey et al. (1986) in which kallikrein-like enzyme activity was shown to peak at around the time of ovulation. This suggests that the study by Gao et al. (1992), which used the more specific substrate, Pro-Phe-Arg-methylcoumarylamide, was in fact detecting true $r K L K 1$ enzyme activity. The reactivity of multiple members of the $r K L K$ gene family with the chromogenic substrate S2266, used by Espey et al. (1986) - which was able to be hydrolysed by not only $r K L K 1$ but also $r K L K 2, r K L K 7$ and $r K L K 9$ 

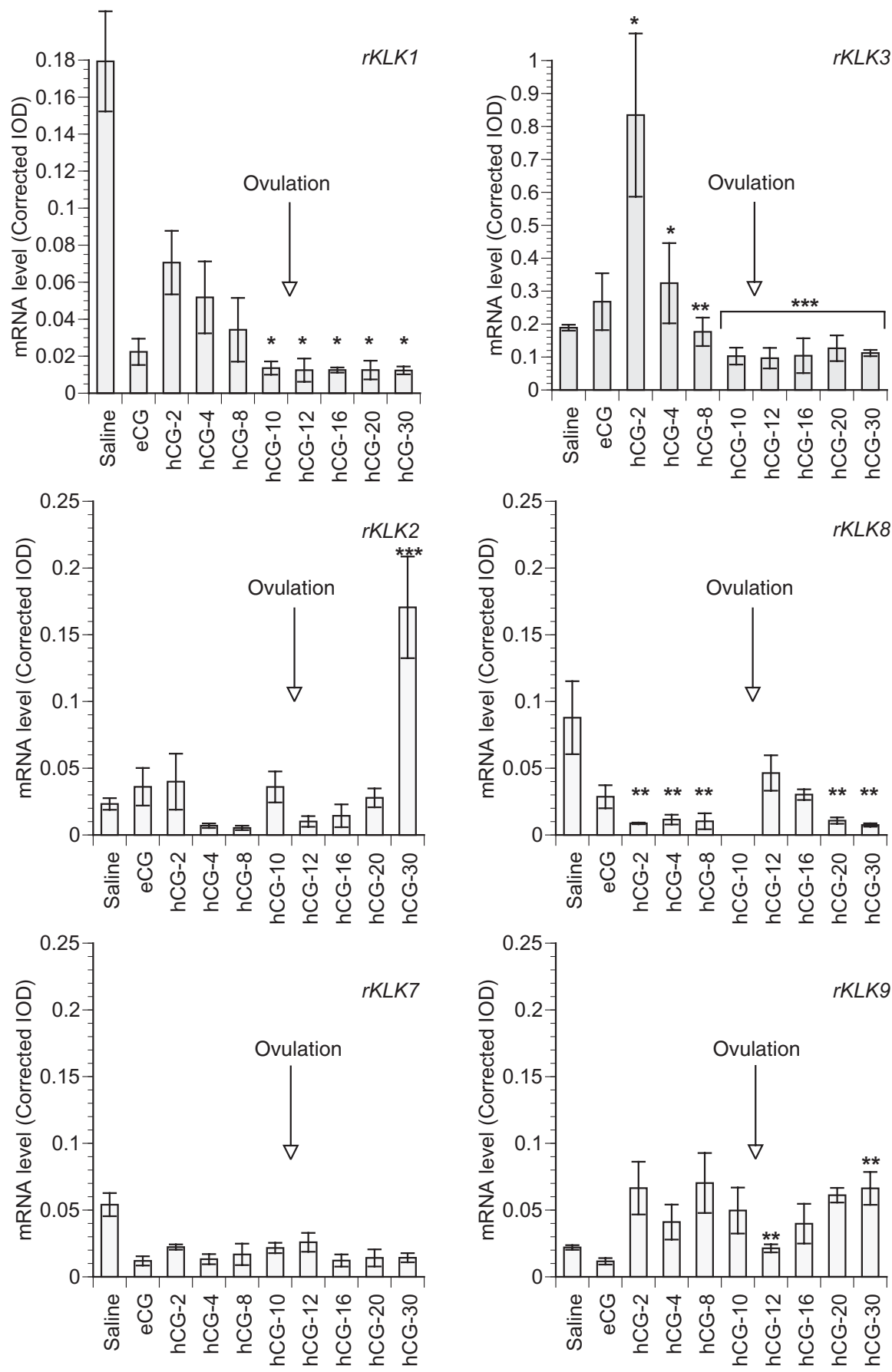

Figure 3 Expression patterns of individual $r K L K$ gene family members in the gonadotrophin-stimulated rat ovary. RNA was obtained from the ovaries of sham-treated controls (saline), and after $48 \mathrm{~h}$ from animals treated with hCG for 0 (eCG), 2 (hCG-2), 4 (hCG-4), 8 (hCG-8), 10 (hCG-10), 12 (hCG-12), 16 (hCG-16), 20 (hCG-20) or 30 h (hCG-30) and subjected to semi-quantitative RT-PCR as described in the text. Expression levels of $r K L K 1, r K L K 2, r K L K 3, r K L K 7, r K L K 8$ and $r K L K 9$ were determined by hybridisation to gene-specific oligonucleotides, phosphorimage analysis and normalisation to $\beta_{2}$-microglobulin expression levels. Arrows indicate the time of ovulation, which occurs at 10-12 h after hCG treatment in this model. Results are shown as corrected integrated optical density (IOD) (mean \pm S.E.M.) as a function of treatment. Statistical analyses for $r K L K 1$, hCG2 compared with hCG-10, -12, -16, -20 and -30; rKLK2, hCG-30 compared with all groups; rKLK3, hCG-2 compared with hCG-4, -8, -10, -12, 16, -20 and -30; rKLK8, saline compared with hCG-2, -4, -8, -20 and -30; rKLK9, hCG-12 compared with hCG-30: ${ }^{*} P<0 \cdot 05,{ }^{*} P<0 \cdot 01,{ }^{* *} P<0 \cdot 001$. 
(Berg et al. 1992, Wang et al. 1992) - is presumably responsible for the different pattern of enzyme activity reported by Espey et al. (1986), although it is unclear from the present study which specific $r K L K$ gene(s) were responsible for the pattern of expression observed by Espey et al. (1986). Clearly, biochemical assays for kallikrein-like enzyme activity will remain severely limited without highly specific enzyme substrates for each enzyme encoded by the $r K L K$ genes.

Bradykinin, the effector peptide generated by the action of tissue kallikrein ( $r K L K 1)$ on its primary substrate low-molecular-weight kininogen, has been shown to stimulate the ovulatory process in in vitro perfused rat and rabbit ovaries (Hellberg et al. 1991, Yoshimura et al. 1994) and is also well characterised for its promotion of vascular permeability at sites of inflammation, leading to oedema (Bhoola et al. 1992). As ovulation has been likened to an inflammatory response, and as the kallikrein-kinin system has also been more recently implicated as having a role in ovarian hyperstimulation syndrome - another inflammatory-like condition of the ovary (Kobayashi et al. 1998, Ujioka et al. 1998) - it is possible that bradykinin plays a similar role in the pre-ovulatory follicle. The increased level of $r K L K 1$ expression after hCG stimulation of the immature rat would thus support such a role for this enzyme. The decrease in $r K L K 1$ expression in the peri-ovulatory period may also be indicative of a downregulation of the vasodilatory role of bradykinin in the post-ovulatory follicle.

As the substrates of other genes detected in this study $(r K L K 3, r K L K 7$ and $r K L K 8)$ are as yet uncharacterised, it is not clear what their potential role(s) may be, although the pre- and peri-ovulatory patterns of expression of $\mathrm{r} K L K 3$ and $r K L K 8$ are particularly intriguing and warrant further investigation. Substrates of $r K L K 2$ and $r K L K 9$ have been determined in vitro which allows some speculation as to their potential roles in the process of ovulation.

Tonin (encoded by $r K L K 2$ ), is able to process angiotensinogen to angiotensin II, in vitro. Angiotensin is believed to play numerous roles in the pre- and postovulatory follicle, including vascularisation of the early follicle, maturation of the oocyte, and regulation of stromal, thecal, granulosa and luteal cell growth and proliferation (Andrade-Gordon et al. 1991, Yoshimura 1997). As $r K L K 2$ levels are not increased at this time, tonin may not be a physiological activator of angiotensin II in the rat ovary and thus it is possible that angiotensin is activated by other factors, such as tissue plasminogen activator in this tissue (Yoshimura 1997). The marked increase in expression of $r K L K 2$ at $20-30 \mathrm{~h}$ after hCG administration may be indicative of a role for this enzyme in the process of luteolysis, particularly in the formation of the vasculature associated with the luteinised granulosa cells (Hillier 1994), although this has yet to be determined.

rKLK9 is known to encode the potent vasoconstrictive agent submandibular enzymatic vasoconstrictor
(Yamaguchi et al. 1991). Although expression of this gene throughout the pre-ovulatory period was highly variable, there was a consistent decrease in the level of its expression at $12-16 \mathrm{~h}$ after hCG stimulation. It is therefore possible to speculate that an increased level of $r K L K 9$ expression in the pre-ovulatory period, and the subsequent decrease at around $12 \mathrm{~h}$ post-hCG, may reflect a role for this enzyme in the control of local blood flow (perhaps in concert with bradykinin and angiotensin II) at around the time of ovulation.

In conclusion, we have identified and characterised the patterns of expression of six members of the highly conserved KLK gene family ( $r K L K 1, r K L K 2, r K L K 3$, $r K L K 7, r K L K 8$, and $r K L K$ 9) throughout the ovulatory process in an ovulatory rat model. It is likely that tissue kallikrein (encoded by $r K L K 1$ ) does play a role in ovulation; however, further studies are required to determine the sites of action, the cell types expressing these enzymes, and the physiological substrates of all of these $K L K$ enzymes in the ovary. These findings will help us to understand the events controlling the regulation of expression of the members of the $K L K$ gene family and further elucidate the roles of these enzymes in the process of ovulation and ovarian function.

\section{Acknowledgements}

The authors are indebted to Associate Professor Peter Fuller for guidance and helpful discussion of this work, Julie McMaster for technical assistance and Sue Panckridge for assistance with figures. The financial support of Prince Henry's Institute of Medical Research $(\mathrm{A} \mathrm{MH})$, the National Health and Medical Research Council of Australia (J K F: No. 983212; J A C: No. 950859) is gratefully acknowledged.

\section{References}

Adashi EY 1998 The potential role of interleukin-1 in the ovulatory process: an evolving hypothesis. Molecular and Cellular Endocrinology $14077-81$.

Andrade-Gordon P, Zreik T, Apa R \& Naftolin F 1991 Role of angiotensin II in the processes leading to ovulation. Biochemical Pharmacology 42 715-719.

Berg T, Schoyen H, Wassdal I, Hull R, Gerskowitch V P \& Toft K 1992 Characterization of a new kallikrein-like enzyme (KLP-S3) of the rat submandibular gland. Biochemical Journal 281 819-828.

Bhoola KD, Figueroa CD \& Worthy K 1992 Bioregulation of kinins: kallikreins, kininogens, and kininases. Pharmacological Reviews 44 $1-80$.

Camp TA, Rahal JO \& Mayo KE 1991 Cellular localization and hormonal regulation of follicle-stimulating hormone and luteinizing hormone receptor messenger RNAs in the rat ovary. Molecular Endocrinology 5 1405-1417.

Chomczynski P \& Sacchi N 1987 Single-step method of RNA isolation by acid guanidinium thiocyanate-phenol-chloroform extraction. Analytical Biochemistry 162 156-159. 
Clements JA 1989 The glandular kallikrein family of enzymes: tissuespecific expression and hormonal regulation. Endocrine Reviews $\mathbf{1 0}$ 393-419.

Clements JA, Mukhtar A, Holland AM, Ehrlich AR \& Fuller PJ 1995 Kallikrein gene family expression in the rat ovary: localization to the granulosa cell. Endocrinology 136 1137-1144.

Clements J, Mukhtar A, Yan S \& Holland A 1997 Kallikreins and kinins in inflammatory-like events in the reproductive tract Pharmacological Research 35 537-540.

Cole T, Dickson PW, Esnard F, Averill S, Risbridger GP, Gauthier F \& Schreiber G 1989 The cDNA structure and expression analysis of the genes for the cysteine proteinase inhibitor cystatin $\mathrm{C}$ and for beta 2 -microglobulin in rat brain. European Journal of Biochemistry $18635-42$.

Espey L 1990 Ovulation as an inflammatory reaction - a hypothesis. Biology of Reproduction 22 73-106.

Espey LL, Miller DH \& Margolius HS 1986 Ovarian increase in kinin-generating capacity in PMSG/hCG-primed immature rat. American Journal of Physiology 251 E362-E365.

Espey LL, Tanaka N, Winn V \& Okamura H 1989 Increase in ovarian kallikrein activity during ovulation in the gonadotrophin-primed immature rat. Journal of Reproduction and Fertility 87 503-508.

Gao X, Greenbaum LM, Mahesh VB \& Brann DW 1992

Characterization of the kinin system in the ovary during ovulation in the rat. Biology of Reproduction 47 945-951.

Hellberg P, Larson L, Olofsson J, Hedin L \& Brannstrom M 1991 Stimulatory effects of bradykinin on the ovulatory process in the in vitro-perfused rat ovary. Biology of Reproduction 44 269-274.

Hillier SG 1994 Hormonal control of folliculogenesis and luteinisation. In Molecular Biology of the Female Reproductive System, pp 1-37. Ed. J K Findlay. San Diego: Academic Press.

Kobayashi H, Okada Y, Asahina T, Gotoh J \& Terao T 1998 The kallikrein-kinin system, but not vascular endothelial growth factor, plays a role in the increased vascular permeability associated with ovarian hyperstimulation syndrome. Journal of Molecular Endocrinology 20 363-374.

Menashi S, Fridman R, Desrivieres S, Lu H, Legrand Y \& Soria C 1994 Regulation of $92-\mathrm{kDa}$ gelatinase B activity in the extracellular matrix by tissue kallikrein. Annals of the New York Academy of Sciences 732 466-468.

Nemeth JA, Zelner DJ, Lang S \& Lee C 1998 Keratinocyte growth factor in the rat ventral prostate: androgen-independent expression. Journal of Endocrinology 156 115-125.

Orly J, Clemens JW, Singer O \& Richards JS 1996 Effects of hormones and protein kinase inhibitors on expression of steroidogenic enzyme promoters in electroporated primary rat granulosa cells. Biology of Reproduction 54 208-218.
Ronen-Fuhrmann T, Timberg R, King SR, Hales KH, Hales DB, Stocco DM \& Orly J 1998 Spatio-temporal expression patterns of steroidogenic acute regulatory protein (StAR) during follicular development in the rat ovary. Endocrinology 139 303-315.

Skinner MK \& Parrott JA 1994 Growth factor-mediated cell-cell interactions in the ovary. In Molecular Biology of the Female Reproductive System, pp 67-81 Ed. J K Findlay. San Diego: Academic Press.

Tamura K, Tamura H, Kumasaka K, Miyajima A, Suga T \& Kogo H 1998 Ovarian immune cells express granulocyte-macrophage colony-stimulating factor (GM-CSF) during follicular growth and luteinization in gonadotropin-primed immature rodents. Molecular and Cellular Endocrinology 142 153-163.

Tanaka N, Espey LL, Stacy S \& Okamura H 1992 Epostane and indomethacin actions on ovarian kallikrein and plasminogen activator activities during ovulation in the gonadotropin-primed immature rat. Biology of Reproduction 46 665-670.

Terranova PF \& Rice VM 1997 Review: cytokine involvement in ovarian processes. American Journal of Reproductive Immunology 37 $50-63$.

Tsafriri A 1995 Ovulation as a tissue remodelling process. Proteolysis and cumulus expansion. Advances in Experimental Medicine and Biology 377 121-140.

Tsafriri A \& Reich R 1999 Molecular aspects of mammalian ovulation. 1-11.

Ujioka T, Matsuura K, Tanaka N \& Okamura H 1998 Involvement of ovarian kinin-kallikrein system in the pathophysiology of ovarian hyperstimulation syndrome: studies in a rat model. Human Reproduction 13 3009-3015.

Wang C, Tang CQ, Zhou GX, Chao L \& Chao J 1992 Biochemical characterization and substrate specificity of rat prostate kallikrein (S3): comparison with tissue kallikrein, tonin and T-kininogenase. Biochimica et Biophysica Acta 1121 309-316.

Yamaguchi T, Carretero OA \& Scicli AG 1991 A novel serine protease with vasoconstrictor activity coded by the kallikrein gene S3. Journal of Biological Chemistry 266 5011-5017.

Yoshimura Y 1997 The ovarian renin-angiotensin system in reproductive physiology. Frontiers in Neuroendocrinology 18 247-291.

Yoshimura Y, Koyama N, Karube M, Oda T, Akiba M, Yoshinaga A, Shiokawa S, Jinno M \& Nakamura Y 1994 Gonadotropin stimulates ovarian renin-angiotensin system in the rabbit. Journal of Clinical Investigation 93 180-187.

Received 7 February 2001

Accepted 1 March 2001 